\title{
A temporal examination of calcium signaling in cancer- from tumorigenesis, to immune evasion, and metastasis
}

\author{
MengMeng $\mathrm{Xu}^{1,2^{* \dagger}}$, Andreas Seas ${ }^{1 \dagger}$, Musa Kiyani ${ }^{3,4+}$, Keven S. Y. Ji ${ }^{3 \dagger}$ and Hannah N. Bell ${ }^{1 \dagger}$
}

\begin{abstract}
Background: Although the study of calcium $\left(\mathrm{Ca}^{2+}\right)$ is classically associated with excitable cells such as myocytes or neurons, the ubiquity of this essential element in all cellular processes has led to interest in other cell types. The importance of $\mathrm{Ca}^{2+}$ to apoptosis, cell signaling, and immune activation is of special import in cancer.

Main: Here we review the current understanding of $\mathrm{Ca}^{2+}$ in each of these processes vital to the initiation, spread, and drug resistance of malignancies. We describe the involvement of $\mathrm{Ca}^{2+}$, and $\mathrm{Ca}^{2+}$ related proteins in cell cycle checkpoints and $\mathrm{Ca}^{2+}$ dependent apoptosis and discuss their roles in cellular immortalization. The role of $\mathrm{Ca}^{2+}$ in intercellular communication is also discussed in relevance to tumor-stromal communication, angiogenesis, and tumor microinvasion. The role that $\mathrm{Ca}^{2+}$ plays in immune surveillance and evasion is also addressed. Finally, we discuss the possibility of targeting $\mathrm{Ca}^{2+}$ singling to address the most pressing topics of cancer treatment: metastatic disease and drug resistance.

Conclusion: This review discusses the current understanding of $\mathrm{Ca}^{2+}$ in cancer. By addressing $\mathrm{Ca}^{2+}$ facilitated angiogenesis, immune evasion, metastasis, and drug resistance, we anticipate future avenues for development of $\mathrm{Ca}^{2+}$ as a nexus of therapy.
\end{abstract}

Keywords: Calcium signaling, Cancer, Immortalization, Tumor-stromal interaction, Metastasis, Drug resistance

\section{Background}

Investigational interest in calcium $\left(\mathrm{Ca}^{2+}\right)$ began over 100 years ago with the discovery of the requirement for $\mathrm{Ca}^{2+}$ in the contraction of rat cardiac muscle [1]. Due to this initial discovery, $\mathrm{Ca}^{2+}$ was thoroughly characterized in ventricular action potential and other muscle cell types before the same basic principles were applied to other excitatory cells types, such as neuronal cells [2]. The importance of active zone localized $\mathrm{Ca}^{2+}$ channels to neurotransmitter release further reinforced the importance of $\mathrm{Ca}^{2+}$ in proper cell function. Today, $\mathrm{Ca}^{2+}$ is known to be an essential element vital to the health and

\footnotetext{
*Correspondence: mengmeng.xu@duke.edu

${ }^{\dagger}$ MengMeng Xu, Andreas Seas, Musa Kiyani, Keven S. Y. Ji and Hannah N. Bell contributed equally to this work

${ }^{1}$ Medical-Scientist Training Program, Duke University Medical Center, Durham, NC 27710, USA

Full list of author information is available at the end of the article
}

function of every cell type. Amplification in the magnitude and duration of $\mathrm{Ca}^{2+}$ changes in the cytosol could mean the difference between cellular migration and cell death $[3,4]$. Similarly, increases in mitochondrial $\mathrm{Ca}^{2+}$ can signal either increased ATP synthesis or trigger cell death [5]. This fine control of cytosolic and organelle $\mathrm{Ca}^{2+}$ levels relies on an intricate symphony between a wide variety of $\mathrm{Ca}^{2+}$ channels pumps and exchangers [2]. In this review, we provide an overview of how disruptions in $\mathrm{Ca}^{2+}$ regulation affect cancer progression, from its involvement in the immortalization of tumor cells, to its role in tumor-stromal interactions and epithelialmesenchymal transition, and finally to current research on $\mathrm{Ca}^{2+}$ in drug resistance.

\section{Role of intracellular $\mathrm{Ca}^{2+}$ in cell cycle and death}

Given the greater than ten-fold gradient between cytosolic $(\sim 100 \mathrm{nM})$ and extracellular $(>1 \mathrm{mM}) \mathrm{Ca}^{2+}$ levels, 
opening of intramembrane $\mathrm{Ca}^{2+}$ channels leads to an immediate influx of $\mathrm{Ca}^{2+}$ [1]. Upon reaching the cytoplasm, $\mathrm{Ca}^{2+}$ often forms complexes with calmodulin to regulate a variety of kinases and cyclins, which regulate cell proliferation and apoptosis $[6,7] . \mathrm{Ca}^{2+}$ regulates global cellular processes in such a way that any disturbances to $\mathrm{Ca}^{2+}$ homeostasis via alterations in expression or folding of $\mathrm{Ca}^{2+}$ channels and $\mathrm{Ca}^{2+}$ binding proteins can disrupt the cell-cycle [8]. As a result, dysregulation of intracellular $\mathrm{Ca}^{2+}$ levels can affect the ability of cells to regulate progression through the cell-cycle and lead to unchecked proliferation and tumorigenesis [9], two of the ten hallmarks of cancer (Fig. 1).

In the normal cell, progression from G1 to S-phase is accomplished via phosphorylation and subsequent inactivation of the tumor suppressor, RetinoBlastoma protein 1 (RB1), as illustrated in Fig. 2 [10]. Endogenous RB1 inactivation or deletion removes this check on the cell cycle and allows affected cells to undergo unchecked DNA synthesis, leading to an accumulation of potentially oncogenic DNA damage. Normally, cytosolic $\mathrm{Ca}^{2+}$ levels modulate the activity of guanosine exchange factor (GEF), a Ras stimulator, and GTPase activating protein (GAP), a Ras inhibitor. When activated, Ras stimulates the proliferative mitogen-activated protein kinase (MAPK) pathway, which results in upregulation of cyclin D1 in the cytoplasm, with ultimate phosphorylation

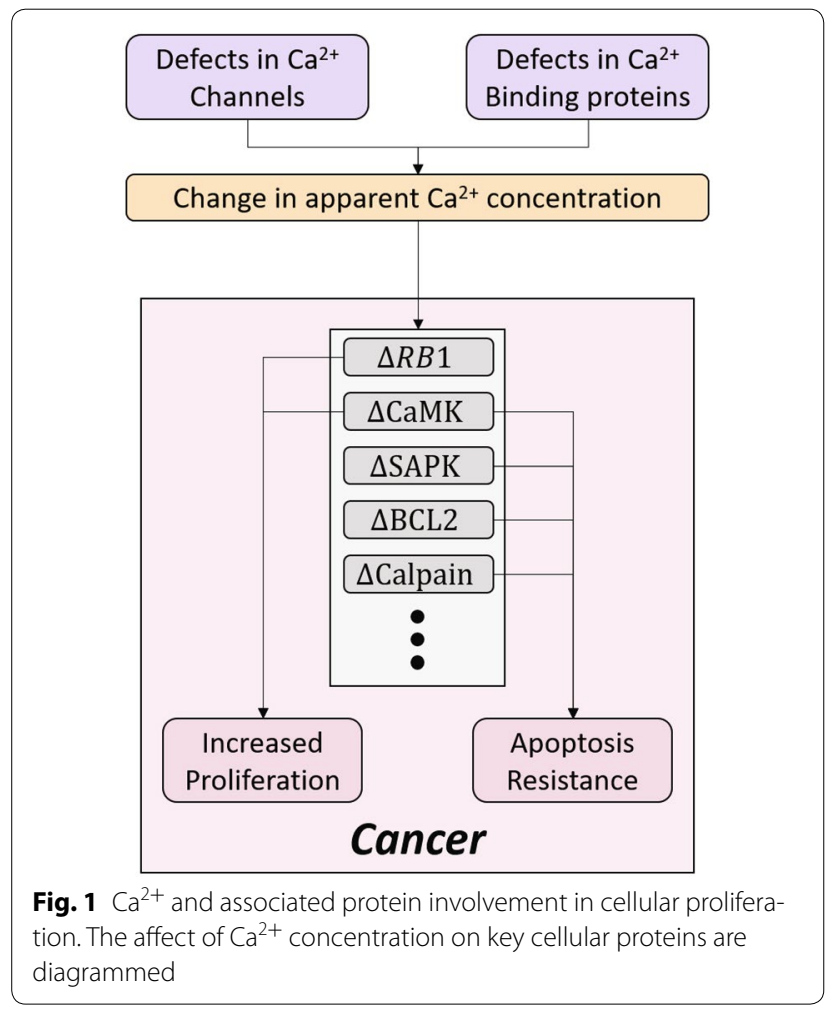

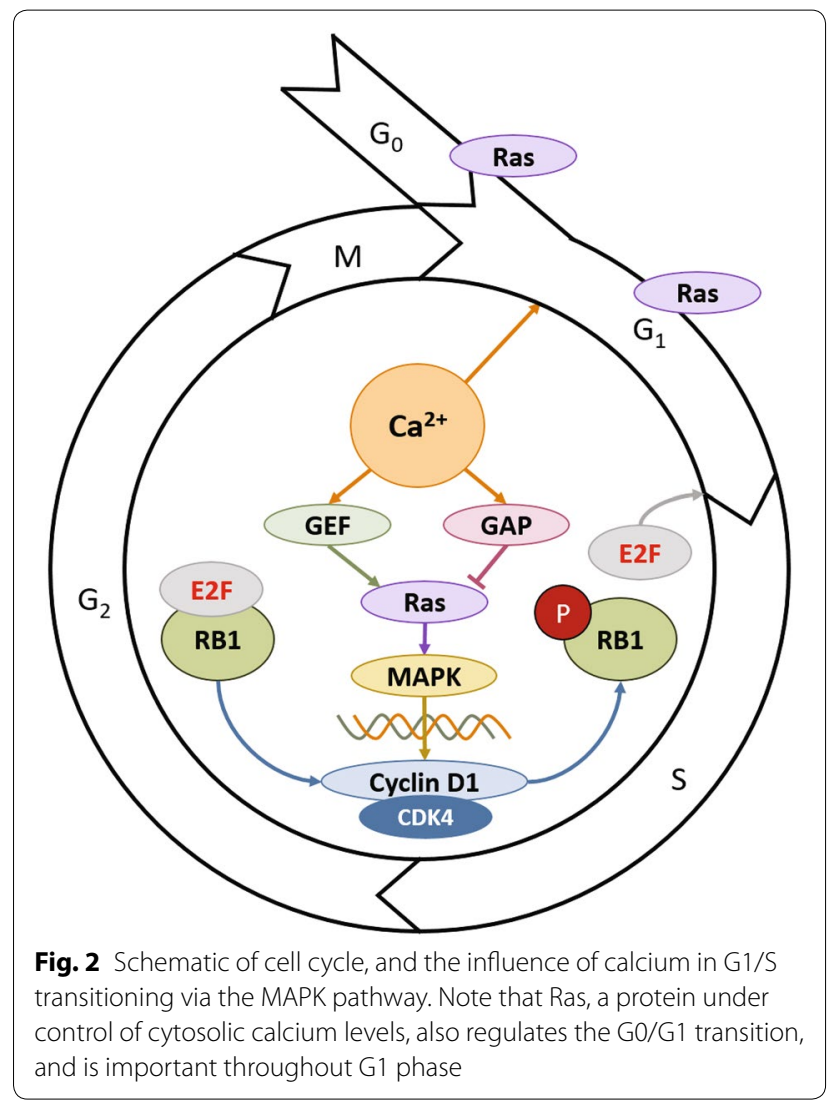

of RB1 and release of the E2F transcription factor which initiates the cells transition into S-phase (Fig. 2). This connection between calcium and RB1 indicates that increased cytosolic $\mathrm{Ca}^{2+}$ levels can lead to constitutive activation of the MAPK pathway, causing removal of the G1-S transition check point. $\mathrm{Ca}^{2+}$ is also involved in signaling entry into $\mathrm{G} 1$, as well as the transition from G2 to $\mathrm{M}$, although the mechanisms of its involvement at these check points are not well understood [11].

Other cell cycle related families, like the $\mathrm{Ca}^{2+} /$ calmodulin-dependent protein kinases (CaMKs) are also known to facilitate proliferation and avoid death by promoting passage through the cell cycle and resisting apoptotic mechanisms [12]. CaMK levels have been shown to vary in lymphoma, ovarian cancer, and hepatocellular carcinoma, among others [13-15].

\section{Changes in $\mathrm{Ca}^{2+}$ conduction and levels can lead to apoptosis evasion and immortalization}

In normal tissue, large, sustained changes to cytosolic $\mathrm{Ca}^{2+}$ can initiate cell death. $\mathrm{Ca}^{2+}$ flux from the endoplasmic reticulum (ER) to the mitochondria can also result in increased mitochondrial sensitivity to apoptotic stimuli. Chronic $\mathrm{Ca}^{2+}$ depletion is also known to cause ER stress and activation of stress activated protein kinases 
(SAPKs), which leads to apoptosis [11]. Finally, high cytosolic levels of $\mathrm{Ca}^{2+}$ can lead to cell death by activating calpain, a cysteine protease that specifically lyses BCL2, an anti-apoptotic regulatory protein $[16,17]$. Alterations in $\mathrm{Ca}^{2+}$ levels can help cancer cells evade the first of these pathways by interrupting the transfer of $\mathrm{Ca}^{2+}$ from the ER to the mitochondria. Specifically, $\mathrm{Ca}^{2+}$-permeable Inositol 1,4,5-triphosphate receptor (IP3R) channels that facilitate this pro-apoptotic flux of $\mathrm{Ca}^{2+}$ from the ER could be prevented form activating. This process is aided by the anti-apoptotic capabilities of BCL-2, which diminishes $\mathrm{Ca}^{2+}$ flux by binding IP3Rs or decreasing $\mathrm{Ca}^{2+}$ levels in the ER lumen $[18,19]$. Certain cancer types are also known to regulate cytosolic $\mathrm{Ca}^{2+}$ to their advantage by bleeding off excess $\mathrm{Ca}^{2+}$ to create pro survival conditions. This is evident in breast cancer, where over-expression of plasma membrane calcium-ATPase 2 (PMCA2) allows for the release of $\mathrm{Ca}^{2+}$ in conditions of $\mathrm{Ca}^{2+}$ overload [20]. Potential therapeutics blocking BCL2 activation, promoting stability of the ER-mitochondrial linkage, or blocking the PMCA2 "emergency-release valve" could induce $\mathrm{Ca}^{2+}$-triggered apoptosis in tumor cells.

\section{Tissue pressure, hypoxia and $\mathrm{H}^{+}$can elicit $\mathrm{Ca}^{2+}$ changes}

The cancer microenvironment consists of two interactive components: neoplastic cells and stroma [21]. The tumor stroma is a complex environment consisting of a noncellular extracellular matrix (ECM), and fibroblasts, epithelial, endothelial, and immune cells [22]. This stroma is responsible for providing the nutrients, $\mathrm{O}_{2}$, and signaling molecules necessary to support tumor growth. In pancreatic adenocarcinoma, transient receptor potential cation channel 1 and 6 (TRPC 1 and TRPC6) are activated by elevated pressure and hypoxia, respectively. This process also leads to $\mathrm{Ca}^{2+}$ entry and subsequent pro-angiogenic signaling cascade $[23,24]$. In hepatocellular cancer cells, hypoxia also activates an $\mathrm{ER} \mathrm{Ca}^{2+}$ sensor, stromal interaction molecule 1 (STIM1), which mediates activation of store-operated $\mathrm{Ca}^{2+}$ entry (SOCE) and leads to upregulation of hypoxia-inducible factor 1 (HIF-1) expression [25, 26]. HIF-1 then promotes release of growth factors (GFs) such as angiopoietin 2, placental GF, and stromal-derived factor 1 to promote angiogenesis [27]. In breast cancer, acid-sensing ion channel 1 (ASIC1) mediates $\mathrm{Ca}^{2+}$ influx. This pathway promotes tumor progression by forming reactive oxidative species and nuclear factor $k B(N F-k B)$. Silencing ASIC1 has been shown to reduce tumor growth and metastasis in xenograft models [28]. Similarly, in pancreatic cancer cells, ASIC1 and ASIC3 mediate acidity-induced $\mathrm{Ca}^{2+}$ influx to promote epithelial-mesenchymal transition. Indeed, knockdown of ASIC1 and ASIC3 has been confirmed to suppress liver and lung metastasis in xenograft models.

\section{$\mathrm{Ca}^{2+}$-dependent tumor-stromal signaling drives angiogenesis}

Communication between tumor and stromal cells has been shown to maintain growth and expansion through $\mathrm{Ca}^{2+}$-dependent signaling [29]. Vascular endothelial growth factor (VEGF) released by tumor cells triggers signal transduction that facilitates $\mathrm{Ca}^{2+}$-activated proliferation in endothelial cells. Upon VEGF receptor 2 activation, phosphoinositide phospholipase $\mathrm{C}$ (PLCY) is phosphorylated, which in turn hydrolyzes phospholipid phosphatidylinositol $(4,5)$-bisphosphate $\left(\mathrm{PIP}_{2}\right)$, resulting in accumulation of diacylglycerol (DAG) and inositol 1,4,5-trisphosphate $\left(\mathrm{IP}_{3}\right)$. Accumulation of $\mathrm{IP}_{3}$ results in increase of intracellular $\mathrm{Ca}^{2+}$ and activation of the proliferative MAPK pathway $[30,31]$. Proliferation in numerous subtypes of breast and gastrointestinal carcinomas, and glioblastomas is dependent upon this process [32-34]. Similarly, basic fibroblast growth factor (BFGF) activates the transient receptor potential cation channel subfamily V member 4 (TRPV4) in endothelial cells to facilitate $\mathrm{Ca}^{2+}$ influx, leading to endothelial cell proliferation, migration and angiogenesis $[35,36]$.

\section{$\mathrm{Ca}^{2+}$-dependent signaling may promote or hinder tumor escape of immune surveillance}

$\mathrm{Ca}^{2+}$ dependent signaling is critical in the functioning of tumor-associated macrophages (TAMs), which have the ability to both sustain tumor growth and exert anti-tumor effects under certain conditions [37]. TAMs induce tumor progression through chemokine ligand 18 (CCL18) production. In breast cancer, CCL18 binds to phosphatidylinositol transfer protein membraneassociated 3 (PITPNM3) at the plasma membrane and induces phosphorylation of PLC $\gamma 1$ and protein kinase $\mathrm{C}$ zeta (PKC $)$. This cascade increases levels of inositol 1,4,5-triphosphate 3-kinase isoform B (IP3KB), which are mediators in the $\mathrm{Ca}^{2+}$ signaling pathway. Indeed, the expression of CCL18 in blood or cancer stroma is associated with metastasis and reduced survival [38]. On the other hand, when $\mathrm{T}$ cell receptors (TCRs) on cytotoxic $\mathrm{T}$ lymphocytes binds to MHC-antigen receptors on a malignant cell, the resultant immune synapse triggers $\mathrm{Ca}^{2+}$ influx in the immune cell, leading to lytic granule release and tumor killing. TCR stimulation can also evoke $\mathrm{Ca}^{2+}$ release from the ER via signaling cascade involving Zeta-chain-associated protein kinase 70 (ZAP-70), lymphocyte-specific protein tyrosine kinase (Lck), linker of activation of T cells (LAT), PLC- $\gamma$, and IP3 $[39,40]$. Similarly, $\mathrm{Ca}^{2+}$ entry through Orail channels is required for release of lytic granules and subsequent tumor cell destruction by natural killer cells [41]. Lastly, recent experiments with chimeric antigen receptor $\mathrm{T}$ (CAR T) cells, which have faster release-rates from 
dying tumor cells than $\mathrm{T}$ cell receptor (TCR) $\mathrm{T}$ cells do, have implied there is no difference in intensity of $\mathrm{Ca}^{2+}$ flux between the two cell types; therefore both trigger the release of tumor-killing particles at the same threshold level of $\mathrm{Ca}^{2+}$ [42]. Interactions between various components of stroma and tumor are shown in Fig. 3.

\section{Tumor Initiation}
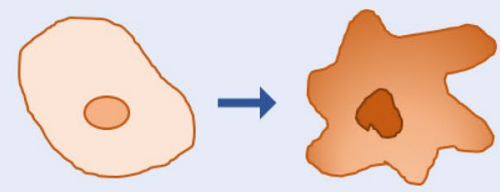

Proliferation- some cell cycle check points are $\mathrm{Ca}^{2+}$ dependent (i.e. RB1 dependence at G1-S checkpoint)

Apoptosis- disruption of $\mathrm{Ca}^{2+}$ dependent cell death pathways (i.e. ER to mitochondria $\mathrm{Ca}^{2+}$ flux)

\section{Tumor Stromal Interaction}

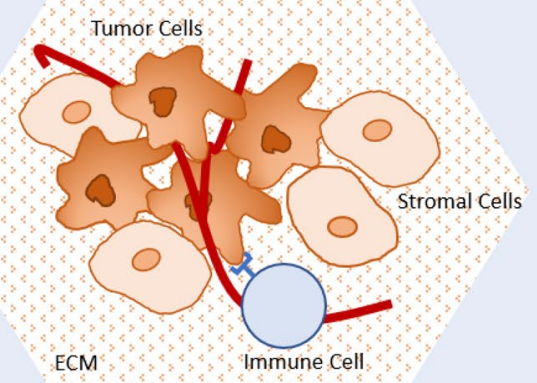

Environmental factors- mechanical stress, hypoxia, and growth factors signal via $\mathrm{Ca}^{2+}$ (i.e. TRPC, STIM1, and ASICs)

Angiogenesis- VEGF activates pro-proliferative $\mathrm{Ca}^{2+}$ signaling in endothelial cells (i.e. PIP $_{2}$-DAG-IP ${ }_{3}$ activation)

Immune Evasion- activation of immune cells can rely on $\mathrm{Ca}^{2+}$ dependent signaling (i.e. Cytotoxic $\mathrm{T}$ lymphocyte rely on $\mathrm{Ca}^{2+}$ to trigger lytic granule release)

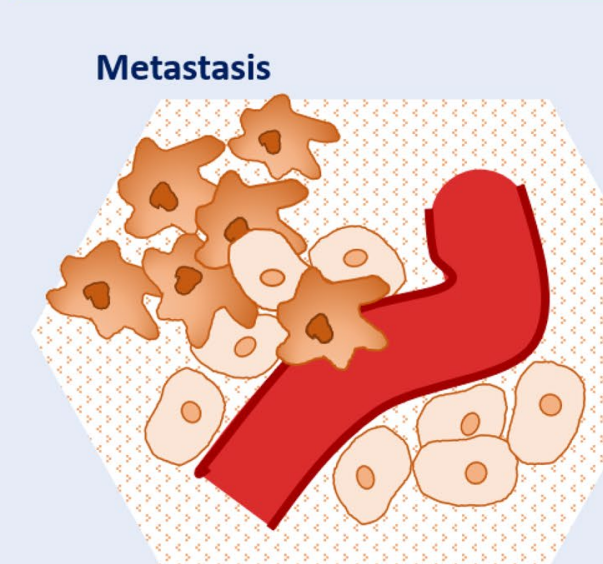

Cell-cell Adhesion- loss of cell-cell connections is the first step to metastasis (i.e. Increased $\mathrm{Ca}^{2+}$ upregulates FAK and increase turnover rate of cell-cell attachments)

ECM Remodeling- Mechanical stress and intracellular $\mathrm{Ca}^{2+}$ levels affect cell-cell adhesion (i.e. $\mathrm{Ca}^{2+}$-dependent TRP proteins regulate ECM remodeling)

Invasion- $\mathrm{Ca}^{2+}$ levels affect tumor cell migration and dedifferentiation at site of metastasis (i.e. Inhibition of SOCE reduces migration and adhesion of cervical cancer)

\section{Drug Resistance}

PMCA2- silencing of PMCA2 reduced cell proliferation and sensitized breast cancer cells to DNA intercalator, doxorubicin

MDR1- this ATP-dependent efflux pump expelling cytotoxic drugs has been associated with chemotherapeutic resistance. Suppression of TRPC5 reduced MDR1 induction and reversed Adriamycin resistance.

Fig. $3 \mathrm{Ca}^{2+}$ signaling in tumor progression. The involvement of $\mathrm{Ca}^{2+}$ in every step of tumor development, metastasis, and current knowledge on $\mathrm{Ca}^{2+}$ facilitated drug resistance 


\section{Developing areas in tumor stromal $\mathrm{Ca}^{2+}$-dependent signaling}

Recent findings on transient receptor potential cation channel subfamily A member 1 (TRPA1) and secreted protein acidic and rich in cysteine (SPARC) point to areas in need of further exploration. In prostate cancer stromal cells, TRPA1 has been shown to act as a mechanosensor and have the ability to bind to Triclosan, an antibacterial agent [43]. This binding increases $\mathrm{Ca}^{2+}$ in stromal cells to trigger subsequent secretion of mitogenic factors, which lead to proliferation and/or migration of adjacent epithelial and endothelial cells to promote angiogenesis [21]. However, the specific stromal ligand activating this function has yet to be discovered. SPARC, a multifunctional, matricellular $\mathrm{Ca}^{2+}$ binding protein, overexpressed in glioblastoma and thyroid, esophageal, hepatocellular, and pancreatic carcinomas, has been clinically correlated with tumor progression [44-47]. SPARC contains an $\mathrm{N}$-terminal low-affinity $\mathrm{Ca}^{2+}$-binding domain and a C-terminal high-affinity $\mathrm{Ca}^{2+}$-binding domain [48]. This protein plays a crucial role in cell rounding and focal adhesion disassembly during angiogenesis, tumor invasion, and metastasis [49]. While the prevalence of $\mathrm{Ca}^{2+}$ binding domains in this protein hint at a role in SPARC function, the exact pathway through which a $\mathrm{Ca}^{2+}$-SPARC complex elicits tumor advancement remains largely unknown [50]. The continued mystery surrounding the mechanism of $\mathrm{Ca}^{2+}$ associated TRPA1 and SPARC function identifies the needs to continued investigation into $\mathrm{Ca}^{2+}$-dependent signaling in the tumor stroma.

\section{Impact of $\mathrm{Ca}^{2+}$ signaling on the epithelial-mesenchymal transition}

The first step in metastasis is the loss of cell-cell connections. Focal adhesion kinase (FAK) is a ubiquitously expressed cytoplasmic tyrosine kinase that increases turnover of cell-cell contacts [51]. Overexpression of FAK is commonly associated with cancer, and seems to induce resistance to anoikis, death due to loss of attachment to a basement membrane. Increased intracellular $\mathrm{Ca}^{2+}$ upregulates FAK at focal adhesions through phosphorylation by the calmodulin-dependent protein kinase II (CaMKII) [52]. Thus, aberrant signaling resulting in elevated intracellular $\mathrm{Ca}^{2+}$ levels can lead to an increase in FAK and a higher turnover rate for cell-cell attachments [53]. Calcineurin, a protein regulated by $\mathrm{Ca}^{2+}$, recycles integrins in migrating cells and is another potential mediator of $\mathrm{Ca}^{2+}$-induced migration [54]. Except for this dysregulation of $\mathrm{Ca}^{2+}$, there are currently no other known differences between normal and malignant cells capable of migration [55].
Mechanical stress and intracellular $\mathrm{Ca}^{2+}$ levels affect cell-cell adhesion through TRP family proteins [56]. In addition to the above described role of TRP in cellular proliferation, TRP also plays a role in the epithelial-mesenchymal transition. High TRP levels are associated with the loss of cell adhesion, while TRP loss is associated with increased strength and number of focal adhesions [57]. Higher expression of TRP family member TRPV1 has been associated with increased migration in many different cancer cell lines $[58,59]$. TRPV2 has also been shown to be an important regulator of matrix metalloproteases MMP2 and MMP9, which are required for the extensive ECM remodeling necessary for successful metastasis [60]. ECM remodeling enzymes are substantially upregulated or specifically induced in many cancers [61]. In addition, many ECM proteins themselves are controlled by calcium levels in the cell. From the glycoprotein fibrinogen which has multiple calcium binding sites critical for structure and function to fibrillin, which has several calcium binding epidermal growth factor domains to the thrombospondins which have multiple calcium binding repeats, calcium is a crucial player in normal physiology of the extracellular matrix. The overall effect of $\mathrm{Ca}^{2+}$ on ECM maintenance and remodeling remains an unanswered question, and an active area of research.

The epithelial-mesenchymal transition (EMT) is also associated with an increased capacity for invasion. This invasive capability has been connected to $\mathrm{Ca}^{2+}$ signaling in some cell types [62]. Davis et al. [63] have shown that when EMT is induced, there is an increase in cytosolic $\mathrm{Ca}^{2+}$ levels in human breast cancer cells. Chelating $\mathrm{Ca}^{2+}$ in this instance reduced epidermal growth factor levels and blocked the induction of EMT markers. Another important contributor to proliferative ability is the SOCE system, through which $\mathrm{Ca}^{2+}$ is pumped into the cytosol when $\mathrm{ER} \mathrm{Ca}^{2+}$ is depleted. SOCE inhibitors have been shown to inhibit migration of cervical cancer and reduce the association of focal adhesion kinases at focal adhesion sites [62].

Extracellular $\mathrm{Ca}^{2+}$ levels have also demonstrated an effect on the re-differentiation of epithelial breast cancer lines. Re-differentiation after metastasis, is important in allowing cancer to survive in a novel niche after metastasis. Although physiological levels of $\mathrm{Ca}^{2+}$ inhibit proliferation and invasion, higher than normal extracellular levels increase estrogen receptor activity, which has been associated with more aggressive and invasive breast cancers [64]. High extracellular $\mathrm{Ca}^{2+}$ levels ultimately increase the risk of bony metastasis in both breast and prostate cancer [65]. 


\section{Targeting $\mathrm{Ca}^{2+}$ as a treatment modality for metastatic disease}

Tumor metastases cause the majority of cancer deaths. As such, development of preventative measures against and treatment of metastasis is an extremely active area of research. Metastatic transformation requires the loss of epithelial cell-cell connections and the transformation of primary tumor cells into a migratory mesenchymal cell. During this process, the cells must also degrade the ECM, cross basement membranes, and enter the circulatory system. As detailed above, $\mathrm{Ca}^{2+}$ signaling is involved in every step of this process [66-68]. Therapeutically, targeting $\mathrm{Ca}^{2+}$ signaling to prevent metastasis is challenging, as any inhibition is likely to impact normal cells as well. Coupling $\mathrm{Ca}^{2+}$ to a cancer specific target has been shown to reduce normal cell death in a prostate cancer study [69]. For example, a drug combining Thapsigargin, a sarcolemma and ER $\mathrm{Ca}^{2+}$-ATPase (SERCA) inhibitor, with the targeting peptide for a prostate-specific antigen was able to limit cell death to prostate cancer cells while sparing normal cells [70]. Despite such technological advances, $\mathrm{Ca}^{2+}$-dependent migration mechanisms between normal and cancerous cells are similar enough that another mode of targeting $\mathrm{Ca}^{2+}$ should be considered [71]. As we have learned from "undruggable" proteins like Ras and Myc, targeting downstream effectors of $\mathrm{Ca}^{2+}$-dependent signaling, such as proteins associated with cell-cell contacts and ECM degradation, may be a more practical approach [72].

\section{Alterations in $\mathrm{Ca}^{2+}$ signaling in settings of drug resistance} In addition to being implicated in the described processes of tumor progression, $\mathrm{Ca}^{2+}$ might also play a significant role in facilitating drug resistance. In a recent study on breast cancer cell lines, increased mRNA levels of plasmalemmal $\mathrm{Ca}^{2+}$ efflux pump (PMCA2), which removes $\mathrm{Ca}^{2+}$ from the cell, was correlated with poor survival [73]. Silencing of PMCA2 reduced cell proliferation and sensitized these cells to doxorubicin. Elevated PMCA2 is commonly found in the mammary glands of lactating mice and may thus indicate high cellular metabolic activity, which is also frequently found in malignant cells. High levels of PMCA2 have also been confirmed in a variety of breast cancer cell lines. Another study confirmed the relationship between high PMCA2 expression and poor outcome, and demonstrated the ability of PMCA2 suppression to sensitize mammary epithelial cells to apoptosis [74].

$P$-glycoprotein or multidrug resistance protein 1 (MDR1), an ATP-dependent efflux pump that expels cytotoxic drugs, has also been associated with chemotherapeutic resistance in breast cancer [75]. Induction of this protein has been associated with upregulation of the
$\mathrm{Ca}^{2+}$-permeable channel TRPC5 in adriamycin-resistant breast cancer cell lines. In both human and mice models, TRPC5 expression is often higher in tumor cells and concentrated to vesicles. Indeed, in the adriamycinresistant breast cancer study, suppressing the activity of pro-oncotic TRPC5 reduced MDR1 induction and reversed adriamycin resistance both in vitro and in vivo [73]. TRPC5 suppression also appears to be essential to drug resistance in colorectal cancer, where suppression of TRPC5 expression reduced MDR1 induction, leading to 5 -FU resistance via the canonical $\mathrm{Wnt} / \beta$-catenin signal pathway.

A subtype of TRPC6 has also been implicated in another malignancy infamously recalcitrant to multiple chemotherapeutic regimens, hepatocellular carcinoma (HCC). A recent study has shown that a subtype of TRPC6, usually expressed at low levels in normal hepatocytes, mediates $\mathrm{Ca}^{2+}$ signaling and drug resistance in HCC. In this study, inhibition of $\mathrm{Ca}^{2+}$ signaling via TRPC6 inhibition resulted in restored sensitivity of HCC cells to various chemotherapeutic drugs and attenuation of the epithelial-mesenchymal transition [76]. These in vitro studies were further corroborated in xenograft models where TRPC6 inhibition enhanced doxorubicin efficacy. The same study also identified the STAT3 pathway as the mechanism of action for TRPC6/Ca ${ }^{2+}$ mediated drug sensitivity. Namely, reduction of intracellular $\mathrm{Ca}^{2+}$ via TRPC6 inhibition activates STAT3, which then stimulates re-differentiation of cells and restores drug sensitivity [77]. T-type $\mathrm{Ca}^{2+}$ channels have also been associated with drug resistance in ovarian and other high-morbidity gynecological malignancies. Experiments on mice models of ovarian cancer have shown mibefradil inhibition of T-type $\mathrm{Ca}^{2+}$ channels to sensitize the disease to carboplatin. Furthermore, both pharmaceutical and genetic inhibition of $\mathrm{Ca}^{2+}$ channels led to apoptotic growth suppression in the ovarian cancer cells [78].

Drug resistance, especially the development of multidrug resistant disease, is of special concern in cancer therapy. The fact that $\mathrm{Ca}^{2+}$-mediated signaling can restore drug sensitivity in breast, colorectal, hepatocellular, and ovarian cancers suggests a possible role for $\mathrm{Ca}^{2+}$ channel blockers as an adjuvant therapy to standard-ofcare chemotherapies.

\section{Conclusions}

From tumor initiation to metastasis and drug resistance, $\mathrm{Ca}^{2+}$ signaling is intrinsic to all aspects of cancer biology (Fig. 3). Ironically, the very ubiquity of $\mathrm{Ca}^{2+}$ signaling in cancer makes this essential element difficult to explore in detail and target for drug development. While multiple studies have shown the importance of $\mathrm{Ca}^{2+}$ signaling at every key disease turning point (immortalization, 
metastasis, and drug response), isolation of the specific effects remains elusive. This suggests development of therapies targeting $\mathrm{Ca}^{2+}$ should be constructed using experience from other "undruggable" targets like Ras and Myc. Instead of targeting $\mathrm{Ca}^{2+}$ itself, known $\mathrm{Ca}^{2+}$ associated proteins such as PMCA2, TRPC5, and MDR1 may serve as more discerning objectives.

Another emerging field of interest for $\mathrm{Ca}^{2+}$ signaling is immunotherapy. Recent publications have suggested that calcium signaling could be used to improve the efficiency of immunotherapy approaches by enhancing antigen presentation and in the adaptive immune response. In addition, the role of $\mathrm{Ca}^{2+}$ in killing by natural killer cells and cytotoxic $\mathrm{T}$ lymphocytes may also be exploited as high levels of intracellular $\mathrm{Ca}^{2+}$ are required for efficient cancer cell killing activity. Conversely, $\mathrm{Ca}^{2+}$ reduction has been showing to reduce growth of malignant cells themselves. Thus, it is necessary to identify the specific $\mathrm{Ca}^{2+}$ channels utilized in granule exocytosis so that immune system's ability to kill malignant cells can be enhanced without simultaneously promoting tumor growth. Although immunotherapy is a promising field through which $\mathrm{Ca}^{2+}$ signaling could augment treatment efficacy, the ubiquity of $\mathrm{Ca}^{2+}$ in normal metabolism and cellular function makes greater understanding of specific mechanisms in $\mathrm{Ca}^{2+}$ signaling necessary before such dreams become attainable.

\begin{abstract}
Abbreviations
ASIC1: acid-sensing ion channel 1; BFGF: basic fibroblast growth factor; CaMKII: $\mathrm{Ca}^{2+} / \mathrm{calmodulin-dependent} \mathrm{protein} \mathrm{kinase} \mathrm{II;} \mathrm{CaMK}_{\mathrm{Ca}} \mathrm{Ca}^{2+} / \mathrm{calmodulin}-$ dependent protein kinases; CCL18: chemokine ligand 18; DAG: diacylglycerol; ECM: extracellular matrix; EMT: epithelial-mesenchymal transition; ER: endoplasmic reticulum; FAK: focal adhesion kinase; HIF-1: hypoxia-inducible factor 1; IP3: inositol 1,4,5-trisphosphate; IP3KB: inositol 1,4,5-triphosphate 3-kinase isoform B; IP3R: 1,4,5-triphosphate receptor; LAT: linker of activation of T cells; Lck: lymphocyte-specific protein tyrosine kinase; MAPK: mitogen-activated protein kinase; MDR1: p-glycoprotein or multidrug resistance protein 1; NF-kB: nuclear factor KB; PIP2: phospholipid phosphatidylinositol $(4,5)$-bisphosphate; PITPNM3: phosphatidylinositol transfer protein membrane-associated 3: PKCZ: protein kinase C zeta; PLCY: phosphoinositide phospholipase C; PMCA2: plasma membrane calcium-ATPase 2, plasmalemmal $\mathrm{Ca}^{2+}$ efflux pump; RB1: retinoblastoma protein 1; SAPK: stress activated protein kinases; SERCA: sarcolemma and ER Ca ${ }^{2+}$-ATPase; SOCE: store-operated $\mathrm{Ca}^{2+}$ entry; SPARC: secreted protein acidic and rich in cysteine; STIM1: stromal interaction molecule 1; TAMs: tumor-associated macrophages; TCRs: T cell receptors; TRPA1: transient receptor potential cation channel subfamily A member 1;TRPC: transient receptor potential cation channel; TRPV4: transient receptor potential cation channel subfamily V member 4; VEGF: vascular endothelial growth factor; ZAP70: zeta-chain-associated protein kinase 70
\end{abstract}

\section{Authors' contributions}

$M X, A S, M K, K S Y J$, and HNB equally contributed to the writing of the manuscript. AS created Figs. 1 and 2. MMX compiled and edited the manuscript and created Fig. 3. All authors read and approved the final manuscript.

\section{Author details}

${ }^{1}$ Medical-Scientist Training Program, Duke University Medical Center, Durham, NC 27710, USA. ${ }^{2}$ Department of Pharmacology and Cancer Biology, Duke University Medical Center, Durham, NC 27710, USA. ${ }^{3}$ School of Medicine,
Duke University Medical Center, Durham, NC 27710, USA. ${ }^{4}$ Duke-NUS Medical School, Singapore 169857, Singapore.

\section{Acknowledgements}

No applicable.

Competing interests

The authors declare that they have no competing interests.

Availability of data and materials

Not applicable.

\section{Consent for publication}

Not applicable.

Ethics approval and consent to participate

Not applicable.

\section{Funding}

Not applicable.

\section{Publisher's Note}

Springer Nature remains neutral with regard to jurisdictional claims in published maps and institutional affiliations.

Received: 2 January 2018 Accepted: 26 March 2018

Published online: 03 April 2018

References

1. Carafoli E. Calcium signaling: a tale for all seasons. Proc Natl Acad Sci USA. 2002;99:1115-22.

2. Berridge MJ, Lipp P, Bootman MD. The versatility and universality of calcium signalling. Nat Rev Mol Cell Biol. 2000;1:11-21.

3. Zhivotovsky B, Orrenius S. Calcium and cell death mechanisms: a perspective from the cell death community. Cell Calcium. 2011;50:211-21.

4. Wei C, Wang X, Chen M, Ouyang K, Song LS, Cheng H. Calcium flickers steer cell migration. Nature. 2009;457:901-5.

5. Di Benedetto G, Scalzotto E, Mongillo M, Pozzan T. Mitochondrial Ca(2) $(+)$ uptake induces cyclic AMP generation in the matrix and modulates organelle ATP levels. Cell Metab. 2013;17:965-75.

6. Humeau J, Bravo-San Pedro JM, Vitale I, Nunez L, Villalobos C, Kroemer G, et al. Calcium signaling and cell cycle: progression or death. Cell Calcium. 2017;70:3-15

7. Kahl CR, Means AR. Calcineurin regulates cyclin D1 accumulation in growth-stimulated fibroblasts. Mol Biol Cell. 2004;15:1833-42.

8. Prevarskaya N, Ouadid-Ahidouch H, Skryma R, Shuba Y. Remodelling of $\mathrm{Ca}^{2+}$ transport in cancer: how it contributes to cancer hallmarks? Philos Trans R Soc Lond B Biol Sci. 2014;369:20130097.

9. Hanahan D, Weinberg RA. Hallmarks of cancer: the next generation. Cell. 2011;144:646-74.

10. Cook SJ, Lockyer PJ. Recent advances in $\mathrm{Ca}(2+)$-dependent Ras regulation and cell proliferation. Cell Calcium. 2006;39:101-12.

11. Roderick HL, Cook SJ. $\mathrm{Ca}^{2+}$ signalling checkpoints in cancer: remodelling $\mathrm{Ca}^{2+}$ for cancer cell proliferation and survival. Nat Rev Cancer. 2008:8:361-75.

12. Rodriguez-Mora O, LaHair MM, Howe CJ, McCubrey JA, Franklin RA. Calcium/calmodulin-dependent protein kinases as potential targets in cancer therapy. Expert Opin Ther Targets. 2005;9:791-808.

13. Gu Y, Zhang J, Ma X, Kim BW, Wang H, Li J, et al. Stabilization of the C-Myc protein by CAMKIlgamma promotes T cell lymphoma. Cancer Cell. 2017;32(115-128):e117.

14. Kritsch D, Hoffmann F, Steinbach D, Jansen L, Mary Photini S, Gajda M, et al. Tribbles 2 mediates cisplatin sensitivity and DNA damage response in epithelial ovarian cancer. Int J Cancer. 2017:141:1600-14.

15. Marcelo KL, Means AR, York B. The Ca(2+)/calmodulin/CaMKK2 axis: nature's metabolic CaMshaft. Trends Endocrinol Metab. 2016:27:706-18. 
16. Wu TT, Peters AA, Tan PT, Roberts-Thomson SJ, Monteith GR. Consequences of activating the calcium-permeable ion channel TRPV1 in breast cancer cells with regulated TRPV1 expression. Cell Calcium. 2014;56:59-67.

17. Akbulut Y, Gaunt HJ, Muraki K, Ludlow MJ, Amer MS, et al. (-)-Englerin A is a potent and selective activator of TRPC 4 and TRPC 5 calcium channels. Angew Chem Int Ed. 2017;54:3787-91.

18. Foyouzi-Youssefi R, Arnaudeau S, Borner C, Kelley WL, Tschopp J, Lew DP, et al. $\mathrm{BCl}-2$ decreases the free $\mathrm{Ca}^{2+}$ concentration within the endoplasmic reticulum. Proc Natl Acad Sci USA. 2000;97:5723-8.

19. Chen R, Valencia I, Zhong F, McColl KS, Roderick HL, Bootman MD, et al. $\mathrm{BCl}-2$ functionally interacts with inositol 1,4,5-trisphosphate receptors to regulate calcium release from the $E R$ in response to inositol 1,4,5-trisphosphate. J Cell Biol. 2004;166:193-203.

20. VanHouten J, Sullivan C, Bazinet C, Ryoo T, Camp R, Rimm DL, et al. PMCA2 regulates apoptosis during mammary gland involution and predicts outcome in breast cancer. Proc Natl Acad Sci USA. 2010;107:11405-10

21. Derouiche $S$, Mariot $P$, Warnier M, Vancauwenberghe $E$, Bidaux G, Gosset $P$, et al. Activation of TRPA 1 channel by antibacterial agent triclosan induces VEGF secretion in human prostate cancer stromal cells. Cancer Prev Res (Phila). 2017;10:177-87.

22. Li H, Fan X, Houghton J. Tumor microenvironment: the role of the tumor stroma in cancer. J Cell Biochem. 2007;101:805-15.

23. Dietrich A, Gudermann T. TRPC6: physiological function and pathophysiological relevance. Handb Exp Pharmacol. 2014;222:157-88.

24. Nielsen N, Kondratska K, Ruck T, Hild B, Kovalenko I, Schimmelpfennig S, et al. TRPC 6 channels modulate the response of pancreatic stellate cells to hypoxia. Pflugers Arch. 2017;469:1567-77.

25. Li Y, Guo B, Xie Q, Ye D, Zhang D, Zhu Y, et al. STIM1 mediates hypoxiadriven hepatocarcinogenesis via interaction with HIF-1. Cell Rep. 2015;12:388-95.

26. Vig M, Peinelt C, Beck A, Koomoa DL, Rabah D, Koblan-Huberson M, et al. CRACM1 is a plasma membrane protein essential for store-operated $\mathrm{Ca}^{2+}$ entry. Science. 2006;312:1220-3.

27. Semenza GL. Cancer-stromal cell interactions mediated by hypoxiainducible factors promote angiogenesis, lymphangiogenesis, and metastasis. Oncogene. 2013;32:4057-63.

28. Gupta SC, Singh R, Asters M, Liu J, Zhang X, Pabbidi MR, et al. Regulation of breast tumorigenesis through acid sensors. Oncogene. 2016;35:4102-11.

29. Mueller MM, Fusenig NE. Friends or foes_-bipolar effects of the tumour stroma in cancer. Nat Rev Cancer. 2004;4:839-49.

30. Wang S, Li X, Parra M, Verdin E, Bassel-Duby R, Olson EN. Control of endothelial cell proliferation and migration by VEGF signaling to histone deacetylase 7. Proc Natl Acad Sci USA. 2008;105:7738-43.

31. Keefe SM, Cohen MA, Brose MS. Targeting vascular endothelial growth factor receptor in thyroid cancer: the intracellular and extracellular implications. Clin Cancer Res. 2010;16:778-83.

32. Brown LF, Berse B, Jackman RW, Tognazzi K, Manseau EJ, Senger DR, et al. Expression of vascular permeability factor (vascular endothelial growth factor) and its receptors in adenocarcinomas of the gastrointestinal tract. Cancer Res. 1993;53:4727-35.

33. Brown LF, Berse B, Jackman RW, Tognazzi K, Guidi AJ, Dvorak HF, et al. Expression of vascular permeability factor (vascular endothelial growth factor) and its receptors in breast cancer. Hum Pathol. 1995;26:86-91.

34. Plate KH, Breier G, Weich HA, Mennel HD, Risau W. Vascular endothelial growth factor and glioma angiogenesis: coordinate induction of VEGF receptors, distribution of VEGF protein and possible in vivo regulatory mechanisms. Int J Cancer. 1994;59:520-9.

35. Antoniotti S, Fiorio Pla A, Pregnolato S, Mottola A, Lovisolo D, Munaron L. Control of endothelial cell proliferation by calcium influx and arachidonic acid metabolism: a pharmacological approach. J Cell Physiol. 2003;197:370-8

36. Liedtke W, Kim C. Functionality of the TRPV subfamily of TRP ion channels: add mechano-TRP and osmo-TRP to the lexicon! Cell Mol Life Sci. 2005;62:2985-3001.

37. Costa da Silva M, Breckwoldt MO, Vinchi F, Correia MP, Stojanovic A, et al. Iron induces anti-tumor activity in tumor-associated macrophages. Front Immunol. 2017;8:1479.
38. Chen J, Yao Y, Gong C, Yu F, Su S, Chen J, et al. CCL18 from tumor-associated macrophages promotes breast cancer metastasis via PITPNM3. Cancer Cell. 2011;19:541-55.

39. Hou X, Pedi L, Diver MM, Long SB. Crystal structure of the calcium releaseactivated calcium channel Orai. Science. 2012;338:1308-13.

40. Schwarz EC, Qu B, Hoth M. Calcium, cancer and killing: the role of calcium in killing cancer cells by cytotoxic T lymphocytes and natural killer cells. Biochim Biophys Acta. 2013;1833:1603-11.

41. Zhou X, Friedmann KS, Lyrmann H, Zhou Y, Schoppmeyer R, et al. A calcium optimum for cytotoxic T lymphocyte and natural killer cell cytotoxicity. J Physiol. 2018. https://doi.org/10.1113/JP274964.

42. Davenport AJ, Cross RS, Watson KA, Liao Y, Shi W, et al. Chimeric antigen receptor $T$ cells form nonclassical and potent immune synapses driving rapid cytotoxicity. Proc Natl Acad Sci. 2018;15:E2068-76.

43. Chen J, Hackos DH. TRPA 1 as a drug target-promise and challenges. Naunyn Schmiedebergs Arch Pharmacol. 2015;388:451-63.

44. Infante JR, Matsubayashi H, Sato N, Tonascia J, Klein AP, Riall TA, et al. Peritumoral fibroblast SPARC expression and patient outcome with resectable pancreatic adenocarcinoma. J Clin Oncol. 2007;25:319-25.

45. Lau CP, Poon RT, Cheung ST, Yu WC, Fan ST. SPARC and Hevin expression correlate with tumour angiogenesis in hepatocellular carcinoma. J Pathol. 2006:210:459-68

46. Sage $E H$, Bornstein P. Extracellular proteins that modulate cell-matrix interactions. SPARC, tenascin, and thrombospondin. J Biol Chem. 1991;266:14831-4.

47. Takano T, Hasegawa Y, Miyauchi A, Matsuzuka F, Yoshida H, Kuma K, et al. Quantitative analysis of osteonectin mRNA in thyroid carcinomas. Endocr J. 2002;49:511-6.

48. Kaleagasioglu F, Berger MR. SIBLINGs and SPARC families: their emerging roles in pancreatic cancer. World J Gastroenterol. 2014;20:14747-59.

49. Framson PE, Sage EH. SPARC and tumor growth: where the seed meets the soil? J Cell Biochem. 2004;92:679-90.

50. Pottgiesser J, Maurer P, Mayer U, Nischt R, Mann K, Timpl R, et al. Changes in calcium and collagen IV binding caused by mutations in the EF hand and other domains of extracellular matrix protein BM-40 (SPARC, osteonectin). J Mol Biol. 1994;238:563-74.

51. Bouchard V, Demers MJ, Thibodeau S, Laquerre V, Fujita N, et al. Fak/ Src signaling in human intestinal epithelial cell survival and anoikis: differentiation state-specific uncoupling with the PI3-K/Akt-1 and MEK/Erk pathways. J Cell Physiol. 2007;212:717-28.

52. Giannone G, Ronde P, Gaire M, Beaudouin J, Haiech J, Ellenberg J, et al. Calcium rises locally trigger focal adhesion disassembly and enhance residency of focal adhesion kinase at focal adhesions. J Biol Chem. 2004:279:28715-23.

53. Tai $Y L$, Chen LC, Shen TL. Emerging roles of focal adhesion kinase in cancer. Biomed Res Int. 2015;2015:690690.

54. Lawson MA, Maxfield FR. Ca(2+)- and calcineurin-dependent recycling of an integrin to the front of migrating neutrophils. Nature. 1995;377:75-9.

55. Prevarskaya N, Skryma R, Shuba Y. Calcium in tumour metastasis: new roles for known actors. Nat Rev Cancer. 2011;11:609-18.

56. Lee J, Ishihara A, Oxford G, Johnson B, Jacobson K. Regulation of cell movement is mediated by stretch-activated calcium channels. Nature. 1999:400:382-6.

57. Su LT, Agapito MA, Li M, Simonson WT, Huttenlocher A, Habas R, et al. TRPM7 regulates cell adhesion by controlling the calcium-dependent protease calpain. J Biol Chem. 2006;281:11260-70.

58. Monet M, Lehen'kyi V, Gackiere F, Firlej V, Vandenberghe M, Roudbaraki $\mathrm{M}$, et al. Role of cationic channel TRPV2 in promoting prostate cancer migration and progression to androgen resistance. Cancer Res. 2010;70:1225-35

59. Waning J, Vriens J, Owsianik G, Stuwe L, Mally S, Fabian A, et al. A novel function of capsaicin-sensitive TRPV1 channels: involvement in cell migration. Cell Calcium. 2007;42:17-25.

60. Monet M, Gkika D, Lehen'kyi V, Pourtier A, Vanden Abeele F, Bidaux G, et al. Lysophospholipids stimulate prostate cancer cell migration via TRPV2 channel activation. Biochim Biophys Acta. 2009;1793:528-39.

61. Jiang M, Qiu J, Zhang L, Lu D, Long M, Chen L, et al. Changes in tension regulates proliferation and migration of fibroblasts by remodeling expression of ECM proteins. Exp Ther Med. 2016;12:1542-50. 
62. White $C$. The regulation of tumor cell invasion and metastasis by endoplasmic reticulum-to-mitochondrial Ca2+ transfer. Front Oncol. 2017;7:171.

63. Davis FM, Azimi I, Faville RA, Peters AA, Jalink K, Putney JW Jr, et al. Induction of epithelial-mesenchymal transition (EMT) in breast cancer cells is calcium signal dependent. Oncogene. 2014;33:2307-16.

64. Journe F, Dumon JC, Kheddoumi N, Fox J, Laios I, Leclercq G, et al. Extracellular calcium downregulates estrogen receptor alpha and increases its transcriptional activity through calcium-sensing receptor in breast cancer cells. Bone. 2004;35:479-88.

65. Insua-Rodriguez J, Oskarsson T. The extracellular matrix in breast cancer. Adv Drug Deliv Rev. 2016;97:41-55.

66. Chen YF, Chiu WT, Chen YT, Lin PY, Huang HJ, Chou CY, et al. Calcium store sensor stromal-interaction molecule 1-dependent signaling plays an important role in cervical cancer growth, migration, and angiogenesis. Proc Natl Acad Sci USA. 2011;108:15225-30.

67. Deliot N, Constantin B. Plasma membrane calcium channels in cancer: alterations and consequences for cell proliferation and migration. Biochim Biophys Acta. 2015;1848:2512-22.

68. Monteith GR, Prevarskaya N, Roberts-Thomson SJ. The calcium-cancer signalling nexus. Nat Rev Cancer. 2017;17:367-80.

69. Cui C, Merritt R, Fu L, Pan Z. Targeting calcium signaling in cancer therapy. Acta Pharm Sin B. 2017;7:3-17.

70. Denmeade SR, Isaacs JT. The SERCA pump as a therapeutic target: making a "smart bomb" for prostate cancer. Cancer Biol Ther. 2005;4:14-22.
71. Chen YF, Chen YT, Chiu WT, Shen MR. Remodeling of calcium signaling in tumor progression. J Biomed Sci. 2013;20:23.

72. Chen YT, Chen YF, Chiu WT, Wang YK, Chang HC, Shen MR. The ER Ca(2) (+) sensor STIM1 regulates actomyosin contractility of migratory cells. J Cell Sci. 2013;126:1260-7.

73. Peters AA, Milevskiy MJ, Lee WC, Curry MC, Smart CE, Saunus JM, et al. The calcium pump plasma membrane $\mathrm{Ca}^{2+}$-ATPase 2 (PMCA2) regulates breast cancer cell proliferation and sensitivity to doxorubicin. Sci Rep. 2016;6:25505.

74. VanHouten J, Sullivan C, Bazinet C, Ryoo T, Camp R, Rimm DL, et al. PMCA2 regulates apoptosis during mammary gland involution and predicts outcome in breast cancer. Proc Natl Acad Sci. 2010;107:11405-10.

75. Holohan C, Van Schaeybroeck S, Longley DB, Johnston PG. Cancer drug resistance: an evolving paradigm. Nat Rev Cancer. 2013;13:714-26.

76. El Boustany C, Bidaux G, Enfissi A, Delcourt P, Prevarskaya N, Capiod T. Capacitative calcium entry and transient receptor potential canonical 6 expression control human hepatoma cell proliferation. Hepatology. 2008;47:2068-77.

77. Courapied S, Sellier H, de Carné Trécesson S, Vigneron A, Bernard AC, Gamelin E, et al. The cdk5 kinase regulates the STAT3 transcription factor to prevent DNA damage upon topoisomerase I inhibition. J Biol Chem. 2010;285:26765-78.

78. Dziegielewska B, Casarez EV, Yang WZ, Gray LS, Dziegielewski J, SlackDavis JK. T-type $\mathrm{Ca}^{2+}$ channel inhibition sensitizes ovarian cancer to carboplatin. Mol Cancer Ther. 2016;15:460-70.

\section{Submit your next manuscript to BioMed Central and we will help you at every step:}

- We accept pre-submission inquiries

- Our selector tool helps you to find the most relevant journal

- We provide round the clock customer support

- Convenient online submission

- Thorough peer review

- Inclusion in PubMed and all major indexing services

- Maximum visibility for your research

Submit your manuscript at www.biomedcentral com/submit 